\title{
ANALISIS DATA HIDROLOGI SUNGAI AIR BENGKULU MENGGUNAKAN METODE STATISTIK
}

\author{
Gusta Gunawan \\ Program Studi Teknik Sipil, Fakultas Teknik, Universitas Bengkulu \\ Jl. WR. Supratman, Kandang Limun Bengkulu 38371 A \\ gusta.gunawan@unib.ac.id
}

\begin{abstract}
Abstrak
Tujuan dari penelitian ini adalah untuk menghitung jumlah debit puncak sungai Air Bengkulu dan pemetaan penyebaran genangan air yang mungkin terjadi di sekitar Air Bengkulu. Analisis curah hujan harian rata-rata dilakukan menggunakan analisis statistik dan curah hujan wilayah dihitung menggunakan metode poligon Thiessen. Data curah hujan yang digunakan untuk keperluan penelitian adalah data hujan selama 15 tahun terakhir. Perhitungan debit puncak menggunakan metode rasional dan simulasi pemodelan banjir dilakukan dengan menggunakan HEC-RAS 4.1.0. Pemetaan genangan banjir dilakukan dengan menggunakan software HecGeoRAS 4.3.1. Hasil analisis statistik menunjukan bahwa distribusi hujan mengikuti distribusi Gumbel tipe 1. Debit puncak Sungai Air Bengkulu untuk periode ulang 5, 10, 25, 50 dan 100 tahun masing-masing 339,66 m3 / detik; 470,38 m3 / detik; 520,59 m3 / detik; 557,83 m3 / detik; 594,79 m3 / detik; $631.62 \mathrm{~m} 3$ / dtk. Hasil pemetaan yang dihasilkan menunjukkan daerah yang terkena banjir genangan di Kota Bengkulu yaitu terjadi pada dataran rendah sepanjang air Bengkulu yang secara administrasi termasuk pada Desa Pasar Bengkulu, Kampung Klawi, Rawa Makmur, Suka Merindu, Tanjung Agung, Tanjung Jaya, dan Semarang. Kedalaman genangan untuk setiap lokasi adalah bervariasi yaitu berada pada kisaran 0,1 sampai dengan 110 $\mathrm{cm}$. Kesimpulan dari penelitian ini adalah genangan banjir di Air Bengkulu terjadi pada beberapa lokasi dengan kedalaman yang berbeda pada setiap lokasinya.
\end{abstract}

Kata Kunci: Banjir, sungai Air Bengkulu, Hec-GeoRAS 4.3.1, HEC-RAS 4.1.0Abstract

Bengkulu municipality as a constituent element of the Air Bengkulu watershed with 51,500 of hectares area bypassed by the stream of Air Bengkulu River which empties into the Teluk Segara District, municipal of Bengkulu. Air Bengkulu River suffered flood at least twice a year of frequency as result of the increase in water discharge $(Q)$ in the rainy season. The purpose of this research is to calculate the amount of peak river discharge of Air Bengkulu and mapping the distribution of inundation water that may occur in the city of Bengkulu. Analysis of the mean daily maximum rainfall area was conducted by Thiessen Polygon using 15 last years of rainfall datas. Calculation of peak discharge using rational methods for different return period plans Analysis of Rainfall of flood modeling simulation is done by using HEC-RAS 4.1.0 and flood inundation mapping is done by using Hec-GeoRAS 4.3.1 flood modeling. The result of rainfall plan calculations was qualified by Gumbel type 1 method. The results of the Air Bengkulu river peak discharge quantify for return period 5, 10, 25, 50 and 100 years respectively 339.66 $\mathrm{m}^{3} / \mathrm{sec} ; 470.38 \mathrm{~m}^{3} / \mathrm{sec} ; 520.59 \mathrm{~m}^{3} / \mathrm{sec} ; 557.83 \mathrm{~m}^{3} / \mathrm{sec} ; 594.79 \mathrm{~m}^{3} / \mathrm{sec} ; 631.62 \mathrm{~m}^{3} / \mathrm{sec}$. Results of generated mapping showed the areas affected by flood inundation in Bengkulu City namely Pasar Bengkulu village, Kampung Klawi, Rawa Makmur, Suka Merindu, Tanjung Agung, Tanjung Jaya, and Semarang. The depth value of inundation mapping for every affected village of floodwaters are vary, but in the range of $0-110 \mathrm{~cm}$.

Keywords: Flood, Air Bengkulu River, Hec-GeoRAS 4.3.1, HEC-RAS 4.1.0 


\section{PENDAHULUAN}

Banjir merupakan fenomena rutin yang dihadapi dengan kerugian yang tidak kecil dan berdampak luas. Publikasi informasi bencana Badan Nasional Penanggulangan Bencana (BNPB) merilis Statistik Bencana Indonesia 2015 yang menerangkan fakta bahwa selama semester pertama tahun ini sudah lebih dari 1000 bencana melanda negeri ini dengan bencana banjir masih memuncaki frekuesi kejadian bencana diberbagai wilayah Indonesia.

Kotamadya Bengkulu sebagai elemen penyusun dari Daerah Aliran Sungai (DAS) Air Bengkulu seluas 51.500 Hektar dilewati oleh aliran Sungai Air Bengkulu yang bermuara di Kecamatan Teluk Segara Kotamadya Bengkulu (Andriansyah \& Mustikasari, 2011). Sungai Air Bengkulu setidaknya mengalami frekuensi banjir dua kali dalam setahun akibat dari kenaikan debit air (Q) di musim penghujan. Akibat banjir yang terjadi sangat menyulitkan masyarakat baik itu di bidang ekonomi seperti halnya lahan perkebunan ataupun lahan persawahan yang terendam, maupun di bidang transportasi seperti halnya jalurjalur darat yang terendam oleh air.

Banjir Sungai Air Bengkulu sering menggenangi areal produktif dan menimbulkan kerugian materil setiap tahunnya, akan tetapi belum banyak dilakukan kajian dan penelitian tentang bagaimana mengetahui daerah sebaran luapan banjir yang berpeluang terjadi serta merepresentasikannnya kedalam citra pemetaan kawasan genangan banjir yang informatif.Oleh karena itu, penelitian tentang pemodelan luapan banjir di daerah hilir aliran Sungai Air Bengkulu akibat dari kenaikan debit air menggunakan perangkat lunak yang berbasis GIS sangat penting untuk dilakukan di Kota Bengkulu.

\section{Hidrologi dan Hidraulika}

Hidrologi adalah ilmu pengetahuan yang mempelajari perilaku air, proses terjadinya, sirkulasi dan distribusi, sifat kimia dan fisika, dan reaksinya dengan lingkunganm termasuk hubungannya dengan kehidupan (Santosa, 1988). Siklus hidrologi adalah proses yang diawali oleh evaporasi/penguapan kemudian terjadinya kondensasi dari awan hasil evaporasi, awan terus terproses sehingga terjadilah hujan yang jatuh ketanah, kemudian air yang jatuh terbagi ada yang run off dan ada yang mengalami infiltrasi / meresap kedalam lapisan tanah, kemudian air mengalir ke laut, danau, sungai, dam kembali terjadi lagi proses penguapan (Hasmar, 2012).

\section{Analisa Curah Hujan}

Data curah hujan yang dipakai untuk perhitungan debit banjir rencana adalah hujan yang terjadi pada Daerah Aliran Sungai (DAS) pada waktu yang sama (Sosrodarsono \& Takeda, 1976).

Beberapa cara pendekatan penentuan series data untuk analisa frekuensi dipilh berdasarkan ketersediaan data yang ada di lapangan dan tentunya masing-masing cara menghasilkan besaran hujan rancangan yang berbeda. Melihat hal ini, dibutuhkan suatu analisa tentang pengaruh cara pendekatan penetapan seri data yaitu cara Maximum Annual Series (MAS) dan Partial Series (PS) terhadap hujan rancangan yang dihasilkan (Handayani, Hendri, \& Aditya, 2013).

\section{Distribusi Curah Hujan Rerata Wilayah}

Metode yang digunakan dalam menghitung curah hujan rata-rata wilayah daerah aliran sungai (DAS) ada tiga metode, yaitu metode rata-rata aritmatik (aljabar), metode poligon Thiessen dan metode Isohyet (Loebis, 1987). Dalam perhitungan distribusi curah hujan rata-rata untuk mendapatkan debit puncak pada DAS Air Bengkulu dilakukan dengan metode poligon thiessen karena metode ini sesuai untuk digunakan pada daearah yang memiliki pos hujan minimal 3 tempat dan tidak tersebar merata. Cara Poligon Thiessen seperti terlihat pada Gambar 1. 


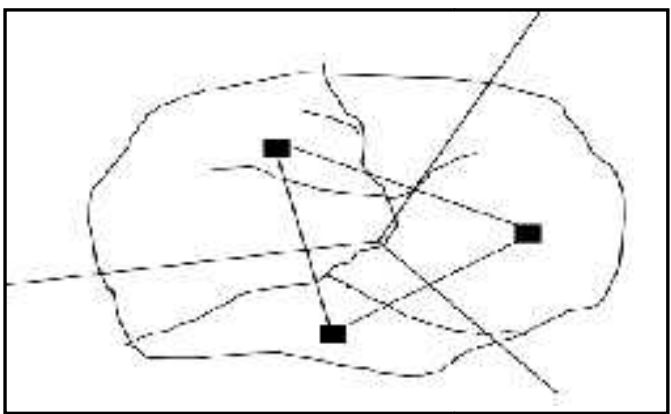

Gambar 1. Cara poligon thiessen

Metode poligon thiessen dipakai apabila daerah pengaruh dan curah hujan rata-rata tiap stasiun berbeda-beda. Metode Thiessen ditentukan dengan cara membuat polygon antar pos hujan pada suatu wilayah DAS, kemudian tinggi hujan rata-rata dihitung dari jumlah perkalian antara tiap-tiap luas polygon dan tinggi hujannya dibagi dengan luas seluruh DAS (Sosrodarsono \& Takeda, 1976).

Persamaan untuk perhitungan hujan rerata wilayah dengan metode poligon thiessen digunakan persamaan sebagai berikut :

$$
\mathrm{R}_{\text {Thiessen }}=\sum_{\mathrm{i}=1}^{\mathrm{n}} \frac{\mathrm{Ai} x \mathrm{Ri}}{\mathrm{A}_{\text {total }}}
$$

\section{Analisa Frekuensi}

Analisa frekuensi bertujuan untuk mencari hubungan antara besarnya besarnya suatu kejadian ekstrem (amksimum atau minimum) dan frekuensinya berdasarkan distribusi probabilitas (Kamiana, 2011).

Secara sistematis metode analisis frekuensi perhitungan hujan rencana ini dilakukan secara berurutan yaitu, parameter statistik, distribusi probabilitas kontinyu, dan pengujian kecocokan sebaran.

\section{Parameter Statistic (Pengukuran dispersi)}

Besarnya derajat dari sebaran variat disekitar nilai rata-ratanya disebut dengan variasi atau dispersi dari pada suatu data sembarang variabel hidrologi. Beberapa macam cara untuk mengukur dispersi dilakukan dengan perhitungan dengan rumus dasar sebagai berikut (Soewarno, 1995):
$\mathrm{Sd}=\sqrt{\left.\frac{\sum_{\mathrm{i}=1}^{\mathrm{n}}\left(\mathrm{X}_{\mathrm{i}}-\overline{\mathrm{X}}\right)^{2}}{\mathrm{n}-1}\right)}$

$\mathrm{Cs}=\frac{\mathrm{n} \sum_{\mathrm{i}=1}^{\mathrm{n}}\left\{\left(\mathrm{X}_{\mathrm{i}}\right)-\overline{\mathrm{X}}\right\}^{2}}{(\mathrm{n}-1)(\mathrm{n}-2) S \mathrm{Sd}^{3}}$

$\left.\mathrm{Ck}=\frac{\frac{1}{\mathrm{n}} \sum_{\mathrm{i}=1}^{\mathrm{n}}\left\{\left(\mathrm{X}_{\mathrm{i}}\right)-\overline{\mathrm{X}}\right\}^{4}}{\mathrm{Sd}^{4}}\right)$

$\mathrm{Cv}=\frac{\mathrm{Sd}}{\overline{\mathrm{X}}}$

\section{Distribusi Probabilitas Kontinyu}

1) Distribusi Gumbel Tipe I

Untuk mengukur curah hujan rencana dengan Distribusi Gumbel Tipe I digunakan persamaan distribusi empiris sebagai berikint (Soewarno, 1995):

$$
X_{T}=-\frac{S}{S_{n}}\left(Y_{T}-Y_{n}\right)
$$

2) Distribusi Log Pearson Tipe III Metode Log Pearson Tipe III apabila digambarkan pada kertas peluang logaritmik akan merupakan persamaan garis lurus, sehingga dapat dinyatakan sebagai model matematik dangan persamaan sebagai berikut (Soewarno, 1995):

$$
\mathrm{Y}=\overline{\mathrm{Y}}+\mathrm{k} \times \mathrm{S}
$$

3) Distribusi Log Normal

Distribusi Log Normal apabila digambarkan pada kertas peluang logaritmik akan merupakan persamaan garis lurus, sehingga dapat dinyatakan sebagai model matematik dengan persamaan sebagai berikut (Soewarno, 1995):

$$
\mathrm{X}_{\mathrm{T}}=\overline{\mathrm{X}}+\mathrm{Kt} \times \mathrm{S}
$$




\section{Pengujian Distribusi Probabilitas}

Uji distribusi probabilitas dimaksudkan untuk mengetahui apa-.kah persamaan distribusi robabilitas yang dipilih dapat mewakili distribusi statistik sampel data yang dianalisis (Kamiana, 2011).

\section{1) Uji Kecocokan Chi-Kuadrat (Chi-} Square)

Pengujian dengan metode ini didasarkan pada jumlah pengamatan yang diharapkan pada pembagian kelas, dan ditentukan terhadap jumlah data pengamatan yang terbaca di dalam kelas tersebut, atau dengan membandingkan nilai Chi-Square $\left(\mathrm{X}^{2}\right)$ dengan nilai ChiSquare kritis $\left(\mathrm{X}^{2} \mathrm{cr}\right)$.

Pengujian kecocokan Chi Kuadrat dengan rumus (Soewarno, 1995):

$$
X^{2}=\sum_{\mathrm{t}=1}^{\mathrm{n}} \frac{(\mathrm{Oi}-\mathrm{Ei})^{2}}{E \mathrm{i}}
$$

Suatu distribusi dikatakan selaras jika nilai $X^{2}$ hitung $<X^{2}$ kritis. Dari hasil pengamatan yang didapat dicari penyimpangan dengan chi-square kritis paling kecil. Untuk suatu nilai nyata tertentu (level of significant) yang sering diambil adalah 5\%. Derajat kebebasan ini secara umum dihitung dengan rumus sebagai berikut (Soewarno, 1995):

$\mathrm{Dk}=\mathrm{K}-(\mathrm{P}+1)$

2) Uji Kecocokan Smirnov-Kolmogorov Pengujian kecocokan sebaran dengan metode ini dilakukan dengan membandingkan probabilitas untuk tiap variabel dari distribusi empiris dan teoritis didapat perbedaan ( ) tertentu. Perbedaan maksimum yang dihitung ( maks) dibandingkan dengan perbedaan kritis ( cr) untuk suatu derajat nyata dan banyaknya variat tertentu, maka sebaran sesuai jika ( maks) < ( cr). Pengujian ini dilakukan dengan menggunakan rumus (Soewarno, 1995):

$$
\alpha=\frac{P_{\text {maks }}}{P_{(x)}}-\frac{P_{(x)}}{c r}
$$

\section{Analisa Intensitas Curah Hujan}

Analisis intensitas curah hujan ini dapat diproses dari data curah hujan yang telah terjadi pada masa lampau. Dengan tersedianya data curah hujan harian, perhitungan curah hujan rencana dapat dilakukan dengan menggunakan rumus Mononobe sebagai berikut :

$$
\mathrm{I}=\frac{\mathrm{R}_{24}}{24} \times\left[\frac{24}{t_{c}}\right]^{2 / 3}
$$

\section{Penentuan Time Of Consentration (Tc)}

Waktu konsentrasi (Time consentration) adalah waktu yang diperlukan air hujan yang jatuh untuk mengalir dari titik terjauh sampai ke titik outlet (titik kontrol). Dalam hal ini diasumsikan bahwa jika durasi hujan sama dengan waktu konsentrasi maka setiap bagian daerah aliran secara serentak telah menyumbangkan aliran terhadap titik kontrol. Salah satu metode untuk memperkirakan waktu konsentrasi adalah dengan rumus yang dikembangkan oleh Kirpich (1940) dalam (Kamiana, 2011), yaitu:

$$
\mathrm{t}_{\mathrm{c}}=0,06628 \times \mathrm{L}^{0,77} \times \mathrm{S}^{-0,385}
$$

\section{Debit}

Debit aliran adalah laju aliran air (dalam bentuk volume air) yang melewati suatu penampang melintang sungai per satuan waktu. Dalam sistem satuan SI besarnya debit dinyatakan dalam satuan meter kubik per detik(m3/dt).Dalam laporan-laporan teknis, debit aliran biasanya ditunjukkan 
dalam bentuk hidrograf aliran (Asdak, 2010).

Pengukuran kecepatan aliran dengan metode ini dapat menghasilkan perkiraan kecepatan aliran yang memadai.Prinsip pengukuran metode ini adalah mengukur kecepatan aliran tiap kedalaman pengukuran (d) pada titik interval tertentu dengan current meter atau flowprobe (Rahayu, 2009)

\section{Analisa Debit Metode Rasional}

Metode Rasional merupakan rumus yang tertua dan yang terkenal di antara rumusrumus empiris. Metode Rasional dapat digunakan untuk menghitung debit puncak sungai atau saluran namun dengan daerah pengaliran yang terbatas (Kamiana, 2011).

Dalam Asdak (2002), dijelaskan jika ukuran daerah pengaliran > 300 ha, maka ukuran daerah pengaliran perlu dibagi menjadi berapa bagian sub daerah pengaliran kemudian Rumus Rasional diaplikasikan pada masing-masing sub daerah pengaliran.

Dalam Montarcih (2009) dijelaskan jika ukuran daerah pengaliran > 5000 Ha maka koefisien pengaliran (C) bisa dipecah-pecah sesuai tata guna lahan dan luas lahan yang bersangkutan. Dalam Suripin (2004) dijelaskan kegunaan Metode Rasional pada daerah pengaliran dengan beberapa sub daerah pengaliran dapat dilakukan dengan pendekatan nilai $\mathrm{C}$ gabungan atau $\mathrm{C}$ ratarata dan intensitas hujan dihitung berdasarkan waktu konsentrasi yang terpanjang.

Persamaan Metode Rasional jika dipergunakan untuk menghitung debit rencana dengan berbagai periode ulang maka notasinya dituliskan :

$\mathrm{Q}_{\mathrm{p}}=0.287 \times \mathrm{C} \times \mathrm{I}_{\mathrm{t}} \times \mathrm{A}$

Menganalisa nilai $\mathrm{C}$ yang sangat dipengaruhi oleh infiltrasi, penguapan, tampungan permukaaan, intensitas dan lama hujan mengakibatkan pemilihan atau perkiraan nilai $\mathrm{C}$ secara tepat sulit dilakukan. Kenyataan di lapangan sangat sulit menemukan daerah pengaliran yang homogen. Dalam kondisi yang demikian, maka nilai $\mathrm{C}$ dihitung dengan cara berikut :

$$
\mathrm{C}=\text { Crerata }=\frac{\sum_{\mathrm{i}=1}^{\mathrm{n}} \mathrm{C}_{\mathrm{i}} \mathrm{A}_{\mathrm{i}}}{\sum_{\mathrm{i}=1}^{\mathrm{n}} \mathrm{A}_{\mathrm{i}}}
$$

\section{METODE PENELITIAN}

\section{Lokasi Penelitian}

Ruang lingkup wilayah penelitian dibatasi pada daerah hilir aliran sungai Air Bengkulu yang berada di Kelurahan Semarang, Tanjung Jaya, Tanjung Agung, Suka Merindu, kampong klawi dan Pasar Bengkulu di dalam Kota Bengkulu.

\section{Pengumpulan Data}

Studi pustaka dilakukan dengan cara mengumpulkan data-data dari instansi terkait, buku-buku, kumpulan jurnal-jurnal dan atau literatur-literatur lainnya yang berhubungan dengan judul yang dibahas guna diperlukan sebagai referensi. Data-data yang akan dikumpulkan adalah sebagai berikut:

1) Data Primer

Pengumpulan data primer pada penelitian ini menggunakan metode survey, yaitu menentukan kecepatan aliran dan profil dasar sungai menggunakan alat Current Meter, identifikasi lahan di sekitar sungai untuk menentukan kekasaran manning dan survei lokasi terdampak luapan bajir di sekitar aliran Sungai Air Bengkulu bagian hilir di dalam Kota Bengkulu.

2) Data Sekunder

Data sekunder yaitu data yang bersifat tidak langsung, akan tetapi memiliki ketekaitan fungsi dan kegunaan dengan salah satu aspek pendukung bagi keabsahan suatu penelitian. Proses pencarian data yaitu dengan mencari berbagai sumber data yang diperlikan untuk melakan penelitian. 


\section{Alat dan Bahan}

1) Alat

Peralatan yang digunakan dalam penelitian ini meliputi perangkat keras (Hardware) dan Perangkat lunak (Software) yang disebutkan berikut:

a. Hardware : Seperangkat Komputer (PC), Printer, Kamera untuk keperluan Dokumentasi, Current Meter, Alat Meteran dan Seperangkat Alat Tulis.

b. Software : ArcMap 9.3, HecGeoRAS 4.31, HEC-RAS 4.10, Microsoft Office 2013 dan Software Google Earth Pro.

2) Bahan

Bahan yang digunakan dalam penelitian antara lain : Data Curah Hujan dari 3 pos hujan selama 15 tahun terakhir (2001 - 2015), Peta DAS Air Bengkulu, DEM SRTM resolusi 1 Arc second (30 $\mathrm{m} \times 30 \mathrm{~m}$ ), Peta RBI tata guna lahan Kota Bengkulu lembar 0912-12 skala 1:50.000, Peta RBI hidrografi lembar 0912-12 skala 1:50.000, Citra Satelit resolusi tinggi (Quickbird quality).

\section{Tahapan Pelaksanaan Penelitian}

Tahapan-tahapan pelaksanaan penelitian yang akan dilakukan meliputi empat tahapan utama yang dijelaskan sebagai berikut :

\section{Pengolahan data hidrologi}

Langkah langkah untuk mengolah data curah hujan hingga diperoleh besaraan debit rencana Metode Raional adalah sebagai berikut :

1) Pengumpulan data primer dan data sekunder.

2) Menganalisa nilai koefisien aliran (C) pada peta tutupan lahan pada Das Bengkulu.

3) Memodelkan Poligon Thiessen untuk DAS Air bengkulu menggunakan ArcMap 9.3. Data yang digunakan adalah poligon batas DAS Air
Bengkulu dan titik koordinat dari 3 stasiun hujan dalam format .shp.

4) Mengolah data curah hujan harian maksimal dari tiga stasiun pos hujan selama periode data 15 tahun untuk mendapatkan curah hujan harian rerata maksimal setiap tahun menggunakan metode poligon Thiessen.

5) Perhitungan curah hujan harian maksimum rerata untuk tiap-tiap tahun data dengan metode Partial Series.

6) Menentukan parameter statistik dari data yang telah diurutkan dari kecil kebesar, yaitu Deviasi standar (Sd), Koefisien kemencengan (Cs), Koefisien Kurtosis (Ck), dan Koefisien variasi (Cv).

a. Hitung nilai rata-rata

$$
\overline{\mathrm{X}}=\frac{\sum_{\mathrm{i}=1}^{\mathrm{n}} \mathrm{Xi}}{\mathrm{n}}
$$

b. Hitung deviasi standar

$$
\mathrm{Sd}=\sqrt{\frac{\sum_{\mathrm{i}=1}^{\mathrm{n}}\left(\mathrm{X}_{\mathrm{i}}-\overline{\mathrm{X}}\right)^{2}}{\mathrm{n}-1}}
$$

c. Hitung koefisien kemencengan

$$
\mathrm{Cs}=\frac{\mathrm{n} \sum_{\mathrm{i}=1}^{\mathrm{n}}\left\{\left(\mathrm{X}_{\mathrm{i}}\right)-\overline{\mathrm{X}}\right\}^{2}}{(\mathrm{n}-1)(\mathrm{n}-2) S \mathrm{Sd}^{3}}
$$

d. Hitung koefisien kurtosis

$$
\mathrm{Ck}=\frac{\frac{1}{\mathrm{n}} \sum_{\mathrm{i}=1}^{\mathrm{n}}\left\{\left(\mathrm{X}_{\mathrm{i}}\right)-\overline{\mathrm{X}}\right\}^{4}}{\mathrm{Sd}^{4}}
$$

e. Hitung koefisien variasi

$$
\mathrm{Cv}=\frac{\mathrm{Sd}}{\overline{\mathrm{X}}}
$$


7) Analisis curah hujan rencana dicoba dengan menggunakan distribusi, yaitu distribusi Gumbel Tipe I, Log Pearson Tipe III, dan Log Normal. Rumus umum yang digunakan

$$
X_{t}=\bar{X}+K t \times S .
$$

8) Uji kecocokan sebaran menggunakan Chi-Kuadrat dan SmirnovKolmogorov, dengan kriteria pengujian: Untuk Uji Chi-Kuadrat jika nilai $\mathrm{f}^{2}$ Hitungan $<\mathrm{F}^{2}$ cr (diterima). Untuk Uji Smirnov-Kolmogorov jika nilai Dmaks < Do kritis (diterima).

9) Penentuan waktu konsentrasi hujan Tc dengan rumus Kirpich.

$$
\mathrm{t}_{\mathrm{c}}=0,06628 \times \mathrm{L}^{0,77} \times \mathrm{S}^{-0,385}
$$

10) Analisis intensitas curah hujan rencana periode ulang $5,10,20,50,100$ dan 200 Tahun, rumus yang digunakan dalam menghitung intensitas hujan adalah rumus Mononobe.

$$
I_{t}=\frac{R_{24}}{24} \times\left[\frac{24}{t_{c}}\right]^{2 / 3}
$$

Menghitung Q (debit) puncak akibat hujan berdasarkan pengaruh tata guna lahan terhadap koefisien pengaliran (C) dengan Intensitas curah hujan rencana menggunakan Metode Rasional mengekspor klik File $\rightarrow$ Export GIS Data $\rightarrow$ Klik Export Data.

\section{HASIL DAN PEMBAHASAN}

\section{Analisa Tutupan Lahan}

Faktor penutupan lahan vegetasi cukup signifikan dalam pengurangan atau peningkatan aliran permukaan. Hutan yang lebat mempunyai tingkat penutup lahan yang tinggi, sehingga apabila hujan turun ke wilayah hujan tersebut, faktor penutupan lahan ini menjadi penghambat limpasan aliran permukaan (surface run off).

Penggunaan lahan pada sub-DAS Rindu Hati dan nilai koefisiennya disajikan pada Tabel 1 berikut :

Tabel 1. Tutupan Lahan sub-DAS Rindu Hati

\begin{tabular}{|l|r|r|c|}
\hline Jenis Tutupan Lahan & Luas (ha) & Persen (\%) & Koefisien \\
\hline Tubuh Air & 32.82 & 0.171 & 1 \\
\hline Hutan Primer & 475.55 & 2.476 & 0.30 \\
\hline Hutan Sekunder & 1176.8 & 6.127 & 0.30 \\
\hline Pertanian Lahan Kering & 16935.07 & 88.167 & 0.35 \\
\hline Pemukiman & 587.76 & 3.060 & 0.40 \\
\hline Total & $\mathbf{1 9 2 0 8}$ & $\mathbf{1 0 0}$ & \\
\hline
\end{tabular}

Sumber: Yudha, 2014

Penggunaan lahan pada Sub-DAS Susup dan nilai koefisiennya disajikan pada Tabel 2 berikut :

Tabel 2. Tutupan Lahan sub-DAS Susup

\begin{tabular}{|l|r|r|c|}
\hline Jenis Tutupan Lahan & Luas (ha) & Persen (\%) & Koefisien \\
\hline Semak Belukar & 645.99 & 6.532 & 0.37 \\
\hline Tanah Terbuka & 16.9 & 0.171 & 0.30 \\
\hline Hutan Sekunder & 842.63 & 8.520 & 0.36 \\
\hline Pertanian Lahan Kering & 8384.48 & 84.770 & 0.41 \\
\hline Total & $\mathbf{9 8 9 0}$ & $\mathbf{1 0 0}$ & \\
Sumber: Yudha, 2014 &
\end{tabular}

Penggunaan lahan pada Sub-DAS Bengkulu Hilir dan nilai koefisiennya disajikan pada Tabel 3 berikut :

Tabel 3. Tutupan Lahan sub-DAS Bengkulu Hilir

\begin{tabular}{|l|r|r|c|}
\hline Jenis Tutupan Lahan & Luas (ha) & Persen (\%) & Koefisien \\
\hline Lahan Kering & 19041.7 & 87.48 & 0.38 \\
\hline Pemukiman & 896.08 & 4.12 & 0.43 \\
\hline Semak Belukar & 448.04 & 2.06 & 0.37 \\
\hline Sawah, Hutan Rawa & 1120.1 & 5.15 & 0.41 \\
\hline Hutan & 260 & 1.19 & 0.36 \\
\hline Total & $\mathbf{2 2 4 0 2}$ & $\mathbf{1 0 0}$ & \\
Sumber: Yudha, 2014
\end{tabular}

\section{Analisa Data Hujan}

Menganalisis data hujan pada prosesnya sangat diperlukan ketersediaan data curah hujan harian yang secara kualitas dan kuantitas cukup memadai. Data curah hujan yang digunakan adalah data curah hujan harian selama 15 tahun terakhir sejak tahun 2001 hingga tahun 2015. 


\section{Analisa hujan harian maksimum rerata} wilayah

Analisa hujan harian maksimum rerata wilayah tahunan $\left(\mathrm{R}_{\text {Thiessen }}\right)$ dilakukan berdasarkan pembobotan curah hujan menurut posisi ketiga stasiun pengukur curah hujan dengan model poligon thiessen. Tahap pertama adalah merekap data curah hujan harian maksimal tiap stasiun hujan yang diperoleh dari instansi terkait.

Data curah hujan tahunan rerata yang sudah diurutkan dapat dilihat pada Tabel 4.

Tabel 4. Data Curah Hujan rerata Tahunan Periode 2001-2015 di tiga pos hujan yang sudah diurutkan.

\begin{tabular}{|c|c|c|}
\hline NO & TAHUN & RHmax rerata \\
\hline 1 & 2013 & 71.96 \\
\hline 2 & 2011 & 95.02 \\
\hline 3 & 2010 & 103.88 \\
\hline 4 & 2012 & 107.66 \\
\hline 5 & 2014 & 110.46 \\
\hline 6 & 2007 & 110.5 \\
\hline 7 & 2003 & 112.37 \\
\hline 8 & 2008 & 114 \\
\hline 9 & 2002 & 116.93 \\
\hline 10 & 2015 & 120.54 \\
\hline 11 & 2001 & 120.72 \\
\hline 12 & 2004 & 124.03 \\
\hline 13 & 2006 & 132.04 \\
\hline 14 & 2005 & 132.62 \\
\hline 15 & 2009 & 137.28 \\
\hline
\end{tabular}

Sumber: Hasil pengolahan, 2016

\section{Analisis Jenis Distribusi}

Metode analisis distribusi yang digunakan untuk menganalisis besar curah hujan rencana harus memenuhi beberapa parameter yang menjadi syarat penggunaan suatu metode distribusi.

Hasil perhitungan curah hujan rencana dapat ditunjukkan pada Tabel 5.
Tabel 5. Rekapitulasi Curah Hujan Rencana

\begin{tabular}{|c|c|c|c|c|}
\hline No & P & $\begin{array}{c}\text { Metode } \\
\text { Gumbel } \\
\text { Tipe I }\end{array}$ & $\begin{array}{c}\text { Metode } \\
\text { Log } \\
\text { Pearson } \\
\text { Tipe III }\end{array}$ & $\begin{array}{c}\text { Metode } \\
\text { Log } \\
\text { Normal }\end{array}$ \\
\hline 1 & 5 & 129.743 & 105.780 & 124.418 \\
\hline 2 & 10 & 141.708 & 134.043 & 134.509 \\
\hline 3 & 25 & 156.832 & 180.285 & 148.181 \\
\hline 4 & 50 & 168.049 & 223.878 & 158.761 \\
\hline 5 & 100 & 179.184 & 276.662 & 170.154 \\
\hline 6 & 200 & 190.282 & 340.868 & 181.385 \\
\hline
\end{tabular}

Sumber: Hasil Perhitungan, 2016

\section{Perhitungan Debit Metode Rasional}

Dalam Montarcih (2009) dijelaskan jika ukuran daerah pengaliran $5000 \mathrm{Ha}$ maka koefisien pengaliran (C) bisa dipecah-pecah sesuai tata guna lahan dan luas lahan yang bersangkutan. Dalam Suripin (2004) dijelaskan penggunaan Metode Rasional pada daerah pengaliran dengan beberapa sub daerah pengaliran dapat dilakukan dengan pendekatan nilai $\mathrm{C}$ gabungan atau $\mathrm{C}$ ratarata dan intensitas hujan dihitung berdasarkan waktu konsentrasi yang terpaSebelum memulai estimasi debit puncak, terlebih dahulu mengidentifikasi nilai Intensitas curah hujan rencana dengan periode ulang T tahun $\left(\mathrm{I}_{\mathrm{t}}\right)$. Data - data yang diperlukan untuk perhitungan seperti nilai inputan panjang saluran utama sungai pada setiap sub DAS dan elevasi saluran pada bagian hulu serta hilir diekstraksi dari peta tutupan lahan dan peta hipsografi (kontur).

Selanjutnya, Perhitungan $\quad I_{t}$ menggunakan persamaan Mononobe yang dimodifikasi untuk tiap sub DAS diuraikan berikut :

1) $I_{t}$ sub DAS Rindu Hati

Data kondisi Sub DAS Rindu Hati berdasarkan hasil analisa GIS dapat dilihat pada Tabel 6. 
Tabel 6. Kondisi Sub DAS Rindu Hati

\section{Data Kondisi Sub DAS Rindu Hati}

\begin{tabular}{|l|l|}
\hline Luas daerah pengaliran (A) & $192.07 \mathrm{~km}^{2}$ \\
\hline Panjang saluran (L) & $34.60 \mathrm{~km}$ \\
\hline Elevasi hulu saluran utama & $190 \mathrm{mdpl}$ \\
\hline Elevasi hilir saluran utama & $18 \mathrm{mdpl}$ \\
\hline \multicolumn{2}{|l|}{ Sumber: Hasil Perhitungan 2016}
\end{tabular}

Perhitungan selengkapnya dapat dilihat pada Tabel 7.

Tabel 7. Hasil perhitungan $I_{t}$ untuk sub DAS Rindu Hati

\begin{tabular}{|c|c|c|c|}
\hline \multirow{2}{*}{ No } & $\begin{array}{c}\text { Periode } \\
\text { Ulang }\end{array}$ & $\mathbf{R}$ & $\mathbf{I}_{\mathbf{t}}$ \\
\cline { 2 - 4 } & (Tahun) & $\mathbf{( m m )}$ & $\mathbf{( m m / j a m )}$ \\
\hline 1 & 5 & 129.743 & 11.41 \\
\hline 2 & 10 & 141.708 & 12.46 \\
\hline 3 & 25 & 156.832 & 13.79 \\
\hline 4 & 50 & 168.049 & 14.78 \\
\hline 5 & 100 & 179.184 & 15.76 \\
\hline 6 & 200 & 190.282 & 16.73 \\
\hline
\end{tabular}

Sumber: Hasil Perhitungan, 2016

2) I sub DAS Susup - Kemumu

Data kondisi Sub DAS Susup - Kemumu berdasarkan hasil analisa GIS dapat dilihat pada Tabel 8 .

Tabel 8. Kondisi Sub DAS Susup-Kemumu Data Kondisi Sub DAS Susup-Kemumu

\begin{tabular}{|l|c|}
\hline Luas daerah pengaliran (A) & $98.90 \mathrm{~km}^{2}$ \\
\hline Panjang saluran (L) & $35.50 \mathrm{~km}$ \\
\hline Elevasi hulu saluran utama & $190 \mathrm{mdpl}$ \\
\hline Elevasi hilir saluran utama & $18 \mathrm{mdpl}$ \\
\hline
\end{tabular}

Sumber: Hasil Perhitungan, 2016

Perhitungan selengkapnya dapat dilihat pada Tabel 9.
Tabel 9. Hasil perhitungan $I_{t}$ untuk sub DAS Susup - Kemumu

\begin{tabular}{|c|c|c|c|}
\hline \multirow{2}{*}{ No } & $\begin{array}{c}\text { Periode } \\
\text { Ulang }\end{array}$ & $\mathbf{R}$ & $\mathbf{I}_{\mathbf{t}}$ \\
\cline { 2 - 4 } & (Tahun) & $\mathbf{( m m )}$ & $\mathbf{( m m / j a m )}$ \\
\hline 1 & 5 & 129.743 & 10.53 \\
\hline 2 & 10 & 141.708 & 11.50 \\
\hline 3 & 25 & 156.832 & 12.73 \\
\hline 4 & 50 & 168.049 & 13.64 \\
\hline 5 & 100 & 179.184 & 14.54 \\
\hline 6 & 200 & 190.282 & 15.44 \\
\hline
\end{tabular}

Sumber: Hasil Perhitungan, 2016

3) $I_{t}$ sub DAS Bengkulu Hilir

Data kondisi Sub DAS Rindu Hati berdasarkan hasil analisa GIS dapat dilihat pada Tabel 10.

Tabel 10. Kondisi Sub DAS Bengkulu Hilir

\section{Data Kondisi Sub DAS Bengkulu Hilir}

Luas daerah pengaliran (A)

\begin{tabular}{|l|c|}
\hline Panjang saluran (L) & $68.15 \mathrm{~km}$ \\
\hline $\begin{array}{l}\text { Elevasi hulu saluran } \\
\text { utama }\end{array}$ & $42 \mathrm{mdpl}$ \\
\hline $\begin{array}{l}\text { Elevasi hilir saluran } \\
\text { utama }\end{array}$ & $10 \mathrm{mdpl}$ \\
\hline
\end{tabular}

Sumber: Hasil Perhitungan, 2016

Perhitungan selengkapnya dapat dilihat pada Tabel 11.

Tabel 11. Hasil perhitungan $I_{t}$ untuk sub DAS Bengkulu hilir

\begin{tabular}{|c|c|c|c|}
\hline \multirow{2}{*}{ No } & $\begin{array}{c}\text { Periode } \\
\text { Ulang }\end{array}$ & $\mathbf{R}$ & $\mathbf{I}_{\mathbf{t}}$ \\
\cline { 2 - 4 } & $\mathbf{( T a h u n )}$ & $\mathbf{( m m )}$ & $\mathbf{( m m / j a m )}$ \\
\hline 1 & 5 & 129.743 & 4.40 \\
\hline 2 & 10 & 141.708 & 4.80 \\
\hline 3 & 25 & 156.832 & 5.31 \\
\hline 4 & 50 & 168.049 & 5.69 \\
\hline 5 & 100 & 179.184 & 6.07 \\
\hline 6 & 200 & 190.282 & 6.45 \\
\hline
\end{tabular}

Sumber: Hasil Perhitungan, 2016

Setelah semua parameter perhitungan di atas didapatkan, maka dapat dilanjutkan dengan 
perhitungan debit puncak rencana metode rasional. Perhitungan debit puncak $\left(\mathrm{Q}_{\mathrm{p}}\right)$ berdasarkan periode ulang rencana untuk setiap sub DAS menggunkan metode rasional. diperoleh hasil debit puncak $\left(\mathrm{Q}_{\mathrm{p}}\right)$ untuk setiap periode ulang yang berbedabeda pada outlet DAS Air Bengkulu. Untuk debit puncak periode ulang 5 tahunan diperoleh hasil $339.66 \mathrm{~m}^{3} / \mathrm{dtk}$ dan untuk debit puncak periode ulang 100 tahunan diperoleh hasil $594.79 \mathrm{~m}^{3} / \mathrm{dtk}$.pada outlet DAS.

\section{KESIMPULAN DAN SARAN}

\section{Kesimpulan}

Adapun dari penelitian ini, dapat disimpulkan :

1. Debit puncak yang didapat pada single outlet DAS Air Bengkulu untuk periode ulang 5, 10, 25, 50, 100, dan 200 tahun dengan Metode Rasional berturut-turut adalah sebesar $339.66 \mathrm{~m}^{3} / \mathrm{dtk} ; 470.38$ $\mathrm{m}^{3} / \mathrm{dtk} ; 520.59 \mathrm{~m}^{3} / \mathrm{dtk} ; 557.83 \mathrm{~m}^{3} / \mathrm{dtk}$; $594.79 \mathrm{~m}^{3} / \mathrm{dtk} ; 631.62 \mathrm{~m}^{3} / \mathrm{dtk}$.

2. Daerah yang terdampak genangan banjir hasil pemetaan oleh HecGeoRAS dan Arcmap yaitu kelurahan Pasar Bengkulu, Kampung Klawi, Rawa Makmur, Suka Merindu, tanjung Agung, Tanjung Jaya, dan Semarang.

3. Nilai kedalaman genangan banjir hasil pemetaan untuk setiap kelurahan yang terdampak genangan banjir sangat bervariasi namun dalam rentang 0 $110 \mathrm{~cm}$.

4. Hasil validasi pemetaan genangan banjir dengan metode membandingkan menggunakan foto dokumentasi ground check saat banjir sesungguhnya sedang terjadi hanya pada kelurahan semarang yang tidak terdampak genangan banjir.

\section{Saran}

Saran yang dapat diberikan dari hasil penelitian ini yaitu beberapa hal i berikut :

1. Dalam anlisa debit metode rasional sebaiknya data tutupan lahan yang digunakan adalah yang terbaru dan terverifikasi sehingga nilai koefisien limpasan (C) yang diperoleh semakin efektif untuk perhitungan besaran debit puncak.

2. Dalam mengkonversi data kontur atau DEM menjadi data TIN harus teliti dalam pengecekan kontur dan terutama garis kontur sungai untuk menghindari terjadinya kesalahan pengeplotan tampang lintang sungai.

3. Sebaiknya saat mensimulasi tampang lintang sungai di $H E C-R A S$, jarak per station dibuat lebih detail agar mendapatkan hasil yang lebih efisien dalam pendekatan simulasi genangan aliran sungai.

4. Perlu penelitian lanjutan dengan data dan informasi yang lebih terukur sehingga hasil simulasi lebih efektif dan mendekati kondisi lapangan yang sebenarnya.

\section{DAFTAR PUSTAKA}

Andriansyah, O., \& Mustikasari, R. (2011).

Gambaran Umum Permasalahan Pengelolaan Air DAS Air Bengkulu. Bogor: Yayasan Telapak.

Arnita, Sari, A. I., Sudarsono, b., Sasmito, b., \& Harianto. (2013). Penentuan Area Luapan Kali Babon Akibat Kenaikan Debit Air Berbasis SIG. Jurnal Geodesi Undip Volume 2 Nomor 4, 57-71.

Aronoff, S. (1989). Geographic Informatio Systems : A management Perspective. Ottawa: WDL Publications.

Asdak, C. (2010). Hidrologi dan Pengelolaan Daerah Aliran Sungai. Yogyakarta: Gajah MAda University Press. 
Barus B, W. U. (2000). Sistem Informasi Geografi - Sarana Manajenem Sumber Daya. Bogor: Lab INDRAJA dan Kartografi FP IPB.

BNPB. (2015). Info Bencana. Jakarta: Pusdatinmas Badan Nasional Penanggulangan Bencana.

DAI. (2007). Panduan Pemetaan Partisipatif. Malang: Environmental Services Program.

ESRI. (1991). Point Interpolation Prosess Wizard. ESRI, Inc.: Arc/view user guide.

ESRI. (2015, October 11). HEC-GeoRAS and ArcGIS. Diambil kembali dari http://www.esri.com/library/fliers/p dfs/hec-georas-arcgis.pdf

Handayani, Y. L., Hendri, A., \& Aditya, A. (2013). Analisa Hujan Rancangan Partial Series dengan Berbagai Panjang Data dan Kala Ulang Hujan. Pekanbaru: Jurusan Teknik Sipil Fakultas Teknik UNRI.

Hasby, F. (2013). Fluids Flow Classification.

Hasmar, H. (2012). Drainase Terapan. Dalam H. Hasmar, Drainase Terapan (hal. 9-10). Yogyakarta: UII Press.

IDEP. (2007). Banjir, Peranan Masyarakat saat terjadi banjir. BALI: Indonesian Development of Education and Permaculture.

Istiarto. (2014). Modul Pelatihan HECRAS : SIMPLE GEOMETRY RIVER. Fakultas Teknik Jurusan Teknik Sipil dan Lingkungan Universitas Gajah Mada: (Tidak Diterbitkan).
Kamiana, I.M. (2011). Teknik Perhitungan Debit Rencana Bangunan Air. Yogyakarta: Graha Ilmu.

Merwade, V. (2012). Tutorial on using HEC-GeoRAS with ArcGIS 10 and HECRAS Modeling. Indiana, USA: School of Civil Engineering, Purdue University.

Pemerintah Kota Bengkulu. (2015, September 17). Bidang geografis. Diambil kembali dari Website Resmi Kota Bengkulu: http://www.bengkulukota.go.id/sela yang-pandang_geografi_pg250.html

Priyana, d. (2013). Model Simulasi Luapan Banjir Sungai Bengawan Solo untuk Optimalisasi Kegiatan Tanggap Darurat Bencana Banjir. Surakarta: UMS.

Rahayu, S. (2009). Monitoring Air Di Daerah Aliran Sungai . Bogor: World Agroforesty Center ICRAF Asia Tenggara.

Santosa, B. (1988). Hidrolika. Jakarta: Erlangga.

Smith , K., \& Ward, R. (1998). Floods: Physical process and human impact, John wiley and Sons. Chichester, USA.

Soewarno. (1995). Hidrologi Aplikasi Metode Statistik Untuk Analisa Data Jilid 1. Bandung: Nova.

Sosrodarsono, S., \& Takeda, K. (1976). Hidrologi Untuk pengairan. Jakarta: PT. Pradnya Paramita.

Syahrir, B. K., \& Kardhana, H. (2009). Banjir dan Upaya Penanggulangannya. Program for Hydro - Meteorogical risk 
mitigation secondary cities in Asia.

Bandung: Indonesia.

Triatmodjo, B. (1993). Hidraulika 1. Yogyakarta: Beta Offset.

US Army Corps Of Engineers. (2015, October 11). Hec-geoRAS. Retrieved from Hidrologic Engineering Center: http://www.hec.usace.army.mil/soft ware/hec-georas/

Utomo, W. (2004). Pemetaan Kawasan Berpotensi Banjir di DAS Kaligarang Semarang dengan menggunakan SIG (Skripsi). Bogor: Institur Pertanian Bogor.

Wijayanti, P. (2013). Analisis keruntuhan bendungan Pacal. e-Jurnal MATRIKS TEKNIK SIPIL Vol. 1 No. 4 Universitas Sebelas Maret, 488495.

Yudha, S. G. (2014). Analisis Kapasitas Sungai dalam Mengendalikan Banjir Dengan Integrasi Antara Metode Rasional Dengan Program WIN-TR. Bengkulu: Universitas Bengkulu. 